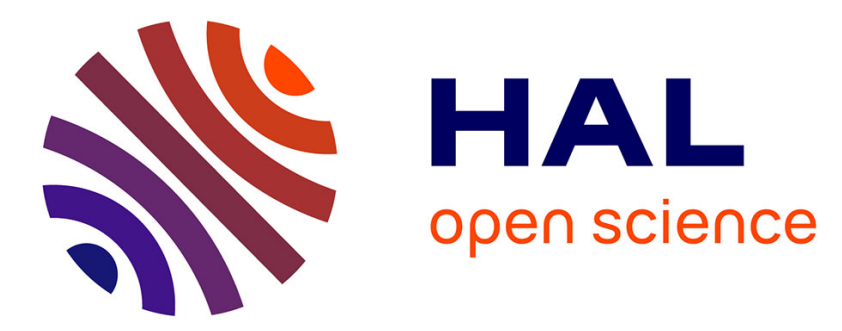

\title{
Potential exposure routes and accumulation kinetics for poly- and perfluorinated alkyl compounds for a freshwater amphipod: Gammarus spp. (Crustacea)
}

D. Bertin, P. Labadie, B.J.D. Ferrari, A. Sapin, J. Garric, Olivier Geffard, H. Budzinski, M. Babut

\section{- To cite this version:}

D. Bertin, P. Labadie, B.J.D. Ferrari, A. Sapin, J. Garric, et al.. Potential exposure routes and accumulation kinetics for poly- and perfluorinated alkyl compounds for a freshwater amphipod: Gammarus spp. (Crustacea). Chemosphere, 2016, 155, pp.380-387. 10.1016/j.chemosphere.2016.04.006 . hal-01868211

\section{HAL Id: hal-01868211 https://hal.science/hal-01868211}

Submitted on 5 Sep 2018

HAL is a multi-disciplinary open access archive for the deposit and dissemination of scientific research documents, whether they are published or not. The documents may come from teaching and research institutions in France or abroad, or from public or private research centers.
L'archive ouverte pluridisciplinaire HAL, est destinée au dépôt et à la diffusion de documents scientifiques de niveau recherche, publiés ou non, émanant des établissements d'enseignement et de recherche français ou étrangers, des laboratoires publics ou privés. 


\section{Potential exposure routes and accumulation kinetics for poly- and perfluorinated alkyl compounds for a freshwater amphipod: \\ Gammarus spp. (Crustacea)}

Delphine Bertin ${ }^{\mathrm{a}}$, Pierre Labadie ${ }^{\mathrm{b}, \mathrm{c}}$, Benoît J. D. Ferrari ${ }^{\mathrm{a}, \mathrm{d}}$, Alexandre Sapin ${ }^{\mathrm{a}}$, Jeanne Garric ${ }^{\mathrm{a}}$, Olivier Geffard $^{\mathrm{a}}$, Hélène Budzinski ${ }^{\mathrm{b}, \mathrm{c}}$, Marc Babut ${ }^{\mathrm{a}^{*}}$.

${ }^{\text {a} I r s t e a, ~ U R ~ M A L Y, ~ C e n t r e ~ d e ~ L y o n-V i l l e u r b a n n e, ~} 5$ rue de la Doua, BP 32108, 69626 Villeurbanne Cedex, France.

${ }^{\mathrm{b}}$ Université de Bordeaux, Environnements et Paléoenvironnements Océaniques et Continentaux (EPOC), UMR 5805 CNRS, Laboratoire de Physico- et Toxico-Chimie de l’environnement (LPTC), 351 cours de la Libération, 33405 Talence, France

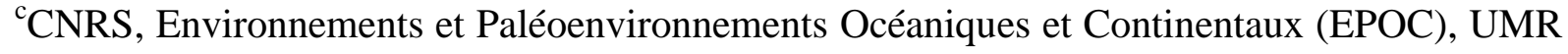
5805 CNRS, Laboratoire de Physico- et Toxico-Chimie de l'environnement (LPTC), 351 cours de la Libération, 33405 Talence, France

${ }^{\mathrm{d}}$ Swiss Centre for Applied Ecotoxicology, Eawag/EPFL, EPFL ENAC IIE-GE, Station 2, CH1015 Lausanne, Switzerland.

(*) Corresponding author: marc.babut@irstea.fr

Present address

- Delphine Bertin - 28 rue Colin, F-69100 Villeurbanne, France; d.bertin@ hotmail.fr

- Alexandre Sapin - Rovaltain Research Company BP 10 313, F-26958 Valence cedex 9, France; asapin@ rovaltainresearch.com 


\section{Highlights}

- Gammarids were exposed to field sediments from downstream of a fluoropolymer plant.

- The steady state was not achieved after 21 days.

- Elimination rates were dependent on the perfluorinated carbon chain length.

- Clearance was high - up to 8-9 perfluorinated carbons.

- Kinetic BSAFs exceeded 1 for compounds having more than 8 perfluorinated carbons.

\section{Abstract}

Gammarids were exposed to sediments from a deposition site located on the Rhône River (France) downstream of a fluoropolymer manufacturing plant. Gammarids accumulated to various extents four long-chain perfluoroalkyl carboxylic acids (PFCAs) from $\mathrm{C}_{9}$ to $\mathrm{C}_{13}$, one sulfonate, perfluorooctane sulfonate (PFOS) and three of its precursors (the perflurooctane sulfonamide (FOSA), the N-methyl perfluorooctane sulfonamidoacetic acid (MeFOSAA), the N-ethyl perfluorooctane sulfonamidoacetic acid (EtFOSAA) and the 6:2 fluorotelomer sulfonic acid (6:2 FTSA). Whatever the compound, the steady state was not achieved after a 3-week exposure; elimination was almost complete after a 3-week depuration period for perfluorononanoic acid (PFNA), PFOS, the three precursors and the 6:2FTSA. However, this was not the case for long-chain PFCAs, whose elimination rates decreased with increasing chain length. PFAS accumulation in gammarids occurred via the trophic and respiratory pathways, in proportions varying with the carbon chain length and the terminal moiety. 


\section{Keywords}

perfluorinated compounds; sediment; Gammarus spp.; exposure route; uptake rate; clearance; BSAF

\section{Introduction}

Poly- and perfluorinated alkyl compounds (PFASs) are present in all media (water, sediment, biota, humans) and are subject to large-scale distribution as far as the polar regions (Giesy and Kannan, 2001; Houde et al., 2006; Houde et al., 2011). Many studies have shown PFASs' bioaccumulation in various species, including top-predators, and a few of them point to sediment as a PFAS source (Martin et al., 2004; Armitage et al., 2006; Loi et al., 2011). In 2009, perfluorooctane sulfonate (PFOS) and related compounds were registered under Annex B of the Stockholm Convention on Persistent Organic Pollutants (http://chm.pops.int/TheConvention/ThePOPs/TheNewPOPs/tabid/2511/Default.aspx).

Although they are located at the basis of many food webs, little is known about PFAS transfer from sediment to benthic organisms. The oligochaete Lumbriculus variegatus accumulated seven perfluoroalkyl carboxylic acids (PFCAs; carbon chain length ranging from $\mathrm{C}_{7}$ to $\mathrm{C}_{14}$ ) and three perfluoroalkane sulfonates (perfluorobutane sulfonic acid - PFBS, perfluorooctane sulfonic acid - PFOS and perfluorodecane sulfonic acid - PFDS) from sediment in two laboratory experiments (Higgins et al., 2007; Lasier et al., 2011). However, the PFAS accumulation pathways and the factors influencing their bioaccumulation were not identified. Two studies of midge (Chironomus riparius) larvae exposed to field sediment showed rapid accumulation and elimination of two PFCAs $\left(\mathrm{C}_{11}\right.$, perfluoroundecanoic acid [PFUnDA] and $\mathrm{C}_{13}$ acid perfluorotridecanoic [PFTrDA]), PFOS and its perfluorooctane sulfonamide precursor (FOSA) (Bertin et al., 2014; Bertin et al., submitted). Like oligochaetes, chironomid larvae are in direct contact with sediment, and accumulation occurs through food ingestion 
and diffusion from pore water (PW) through the tegument. Biota to sediment accumulation factors (BSAFs) for chironomids were lower than BSAFs reported previously for Lumbriculus variegatus (Higgins et al., 2007; Lasier et al., 2011). This difference could be related to the respective experimental designs (uncontaminated food added to chironomids experiments), to physiology, or to differing life traits, in particular feeding habits (Bertin et al., submitted). We found no study addressing these issues for PFASs.

The Gammarus sp. is a freshwater invertebrate widely used in ecotoxicology. It is a widespread epi-benthic species, present throughout the Northern hemisphere. Furthermore, this species is an important food source for fish, amphibians and birds (MacNeil et al., 1997). It feeds mainly by shredding the leaf litter (Tachet et al., 2010). This behaviour plays an important role in the nutrient cycle and contributes to redistributing organic matter in the riverine ecosystem. In addition, gammarids graze organic biofilm at the litter surface, and ingest fine organic matter particulates from sediment deposits. They can also adopt a predator position (MacNeil et al., 1997). Gammarids are also known for their capacity to accumulate various organic and inorganic contaminants (Amiard et al., 1987; Ashauer et al., 2010; Lebrun et al., 2011; Tlili et al., 2012).

The aim of the present study was to determine the PFAS accumulation pathways and kinetics in a benthic species, Gammarus sp. in realistic conditions, because its biology and life traits differ from those previously studied. The objectives were (i) to identify the contamination routes in the accumulation of PFASs by gammarids, (ii) to describe PFAS accumulation and elimination kinetics and (iii) to compare the kinetic constants and BSAFs obtained for gammarids to those available for other benthic species and to discuss the differences according to the respective life traits and physiology.

\section{Materials and methods}




\subsection{Sediments}

In October 2013, a sample of approximately $60 \mathrm{~L}$ of sediment was taken from the river bed of

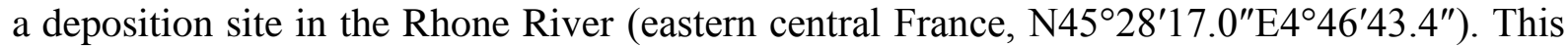
site is located $40 \mathrm{~km}$ downstream of a fluoropolymer manufacturing plant, where polyvinylidene fluoride (PVDF) and various fluorinated polymers have been synthesized since the 1980s (Dauchy et al., 2012). The known releases from this site include mainly a range of perfluoroalkyl acids, in particular the perfluorohexanoic (PFHxA) and perfluorononanoic acids (PFNA), used as a carrier (solvent) of fluorinated polymers. Some longer chain perfluoroalkyl acids, such as the perfluoroundecanoic and perfluorotridecanoic acids (PFUnDA, PFTrDA respectively), are believed to be impurities of the technical PFNA. Surface sediment was collected using a Van-Veen grab, sieved at $2 \mathrm{~mm}$, pooled in a polypropylene (PP) jar and stored at $4^{\circ} \mathrm{C}$ in the laboratory. Twelve aquaria $(38 \times 20 \times 24.5 \mathrm{~cm}$ in polystyrene) were prepared with $4 \mathrm{~L}$ of homogenized sediment and $15 \mathrm{~L}$ of groundwater with $400-500 \mu{\mathrm{S} . \mathrm{cm}^{-1}}^{-1}$ conductivity. Each aquarium was allowed to settle for 1 week before introducing the gammarids. Twelve aquaria were prepared with only groundwater for the controls.

\subsection{Collection and maintenance of gammarids}

Three weeks before the start of the experiment, adult gammarids, i.e. a mixture of Gammarus fossarum and Gammarus pulex, $(9.5 \pm 0.8 \mathrm{~mm})$ were collected with a hand net at a remote/uncontaminated site (La Mouge River, N4650'97.2”E475'63.9”). Gammarids were kept in a bucket on ice, and brought to the laboratory. They were acclimatized for 3 weeks in aquaria with continuously renewed groundwater under constant aeration; a 16:8 h light:dark photoperiod was maintained and the temperature was kept at $12^{\circ} \mathrm{C}$. Organisms were fed ad libitum with alder leaves (Alnus glutinosa). 


\subsection{Gammarus sp. exposure}

One experiment was conducted in two phases: the first step examined PFAS accumulation kinetics while the second step considered PFAS elimination (Figure S1 in SI). Only male gammarids were selected, in order to eliminate potential biases due to neonate release by females. For the accumulation step, 450 individuals were added to nine sediment aquaria (50 per aquarium) and 150 individuals were added to three control aquaria (50 organisms per aquarium). All the aquaria were made in polystyrene (PS) materials; flexible pipes were made of low-density poly-ethylene (PE, Versilic @). Gammarids were collected at 7 (T1), 15 (T2) and 21 (T3) days, one aquarium being sacrificed at each time. For the elimination step, 450 gammarids were added to three sediment aquaria (150/aq.) and exposed for 21 days. After 3 weeks of sediment exposure, the organisms were transferred to a clean media (about 450 organisms in three flow-through aquaria filled with groundwater completely renewed four times per day). About 50 gammarids were killed at 7 (T4), 15 (T5), and 21 (T6) days after the transfer. The control gammarids were also killed after 42 days (Te, about 50 organisms). For both experiments, overlying water (OW) was continuously renewed (four times a day) under constant aeration. A 16:8 h light:dark photoperiod and a temperature of $12^{\circ} \mathrm{C}$ were maintained during the experiments. The organisms were fed ad libitum with alder leaves (Alnus glutinosa), previously conditioned for 3 days in groundwater; freshly pre-conditioned leaves were added once a week. Each week the water quality parameters $(\mathrm{pH}$, temperature, concentration of dissolved oxygen, conductivity, $\mathrm{NO}_{2}^{-}$and $\mathrm{NH}_{4}^{+}$) were monitored (experimental design shown in Fig. S1).

\subsection{Sample collection}

Overlying water $(\mathrm{OW})$ was sampled directly in a $1 \mathrm{~L}$ polyethylene $(\mathrm{PE})$ bottle at $\mathrm{T} 1, \mathrm{~T} 2, \mathrm{~T} 3$, T4, T5, T6 and in the controls. PW was obtained with Rhizon ${ }^{\circledR}$ systems (SDEC, Reignac-sur- 
Indre, France) following the method developed in (Seeberg-Elverfeldt et al., 2005) and was sampled at T1, T2 and T3. Sediment was also sampled at T1, T2 and T3. Leaves were sampled at T0, T1, T2, T3, T4, T5, T6 and once in the controls. Before freezing, leaf samples were rinsed with groundwater to remove sediment particles. Like the leaf samples, organisms were sampled at T0, T1, T2, T3, T4, T5, T6 and in the controls. Then these biota samples were cryopreserved in liquid nitrogen and stored at $-21^{\circ} \mathrm{C}$ (Reiner et al., 2012).

\subsection{PFAS extraction}

For sediment, gammarid samples, leaf samples and the fish tissues used as reference matrix (NIST SRM 1947, Reiner et al., 2012), PFASs were extracted using sonication following the method described in Bertin et al. (2014). The OW and PW samples were processed using Strata-X-AW cartridges as described by Labadie and Chevreuil (2011). Sediment or tissue samples were extracted by sonication using methanol $(\mathrm{MeOH})$, concentrated under a nitrogen stream, purified on ENVI-Carb cartridges and eluted with $\mathrm{MeOH}$. Eluates were concentrated to $400 \mu \mathrm{l}$ under a nitrogen stream and transferred into injection vials. Details are provided in SI.

\subsection{LC-MS/MS analysis and chemicals}

PFASs (list of compounds and acronyms in SI, table S1) were analysed by LC-MS/MS using an Agilent 1200 LC system (Agilent Technology, Massy, France) interfaced with an Agilent 6490 triple quadrupole mass spectrometer (details in SI, Table S2). The purchase of the chemicals and their source are described in the supplementary data; most were purchased from Wellington Laboratories (via BCP Instruments, Irigny, France) and Sigma-Aldrich (St Quentin Fallavier, France).

2.7. Quality control and method performance 
Analyte recovery was determined using spiked samples for each matrix (OW and PW, sediment and gammarids). Native PFAS recovery ranged from $73 \%$ to $122 \%$ with a relative standard deviation below 33\% for fish and spiked sand except for perfluoropentanoic acid (PFPeA) and PFBS. Native PFAS recovery for spiked waters (OW and PW) ranged from 65\% to $118 \%$ with a relative standard deviation below $12 \%$ except PFTrDA, perfluorotetradecanoic acid (PFTeDA), 6:2 fluorotelomer sulfonic acid (6:2 FTSA), N-ethyl perfluorooctane sulfonamidoacetic acid (EtFOSAA), N-methyl perfluorooctane sulfonamide (MeFOSA) and N-ethyl perfluorooctane sulfonamide (EtFOSA) (Table S3 in SI).

Replicate procedural blanks were analysed for each series of samples (details in Table S4 in SI). For the water sample procedure, the predominant compound was PFPeA (mean level: 160 $\pm 8 \mathrm{pg}, n=4)$ and perfluorodecanoic acid (PFDA) (mean level: $34 \pm 5 \mathrm{pg}, n=4)$. For tissue, sediment and leaf samples, the prevailing analytes in blanks were PFPeA (123 pg) and PFDA (31 pg). PFAS concentrations were therefore blank-corrected when applicable. For compounds present in blanks, the limits of detection (LDs) were defined as three times the standard deviation, and the limits of quantification (LQs) were set at 10 times the standard deviation of the blank (Muir and Sverko, 2006; Munoz et al., 2015). For analytes not detected in blanks, LDs and LQs were determined as the concentration with a signal-to-noise ratio of 3 and 9, respectively. This was calculated on matrices spiked at $0.3-1.8 \mathrm{ng} \mathrm{g}^{-1}$ (sediment and Gammarus spp.) and 0.9-17.3 $\mathrm{ng} \mathrm{L}^{-1}$ (Vittel® mineral water samples) (Table S6). The PFASs measured in NIST SRM 1947 Lake Michigan Fish Tissue compared well with reference values (SI Table S6).

2.8. Data analyses and modelling 
Data were checked for normality using the Shapiro-Wilk test and were analysed using the Kruskal-Wallis test (a non-parametric test) and the Mann-Whitney test using $\mathrm{R}$ language (R Core Team, 2014a, b).

Assuming sediment was the main source of PFASs for the gammarids, accumulation data were adjusted to a two-compartment model (Spacie and Hamelink, 1985; Landrum, 1989). Equation (1) was used to estimate the uptake and elimination coefficients $\left(k_{u}\right.$ and $k_{e}$, respectively).

$\frac{d C_{\text {org }}}{d t}=k_{u} \times C_{\text {sed }}-k_{e} \times C_{\text {org }}$

with $C_{\text {org }}$ the PFAS concentration in organisms $\left(\mathrm{ng} \cdot \mathrm{g}^{-1} \mathrm{ww}\right), C_{\text {sed }}$ the PFAS concentration in sediment (ng g $\left.\mathrm{g}^{-1} \mathrm{dw}\right), k_{u}$ expressed in $\mathrm{g} \mathrm{g}^{-1}{ }_{\mathrm{ww}} \cdot \mathrm{d}^{-1}$ and $k_{e}$ in $\mathrm{d}^{-1}$. In the selected size range, gammarids do not grow significantly within the experiment duration, so there is no need to correct for growth.

Elimination data can also be adjusted directly to an exponential decrease model (Eq. 2).

$C_{\text {org }}(t)=C_{0} \cdot e^{-k_{e} t}$

Eq. (2)

where $\mathrm{C}_{0}$ is the PFAS concentration at the start of the elimination phase (ng $\left.\mathrm{g}^{-1} \mathrm{ww}\right)$. Conceptually, $k_{e}$ values obtained from Eqs. 1 and 2 are identical: Eq. 2 corresponds to the integrated form of Eq. 1 when $C s_{e d}$ is set to 0. Nevertheless $k_{e}$ values obtained from the two approaches can differ when fitted on independent data sets. Model calculations were performed in $\mathrm{R}$ language using the <<ode>> function, and $k_{u}$ and $k_{e}$ were optimized simultaneously with the least square method using the <<optim>> function implemented in the $<<$ Desolve $>>$ package (R Core Team, 2014a). When $k_{u}$ and $k_{e}$ are processed in this way, the whole data set including both uptake and elimination experimental data can be used, avoiding differences in $k_{e}$ values derived from separate adjustments. 
The kinetic biota-to-sediment accumulation factor $\left(\mathrm{BSAF}_{\text {kinetic }}\right)$ is derived from the uptake and elimination rate constants (Eq. 3):

\section{Results}

Water in control aquaria displayed low concentrations of PFHpA, PFOA, PFNA, PFDA, PFUnDA, as well as perfluorohexane sulfonate (PFHxS), PFOS and 6:2FTSA $(0.01-0.07 \mathrm{ng}$

PFBS and PFOS were within the range 1.0-5.0 $\mathrm{ng} \mathrm{L}^{-1}$, with other compounds undetected (e.g.

PFOA, PFTrDA, PFBS, PFHxS and PFOS concentrations were within the range $0.5-1.5 \mathrm{ng} \mathrm{L}$

${ }^{1}$. The concentrations of other compounds, including PFNA, PFUnDA and 6:2FTSA were < 
$\left(0.63 \pm 0.38 \mathrm{ng} \mathrm{g}^{-1} \mathrm{dw}\right)$ displayed the highest concentrations in alder leaves; PFPA, PFOA, PFNA, and EtFOSAA ranged from 0.05 to $0.5 \mathrm{ng} \mathrm{g}^{-1} \mathrm{dw}$. PFHxA, PFDoDA, PFHxS,

MeFOSAA and FOSA were measured at levels $<0.05 \mathrm{ng} \mathrm{g}^{-1} \mathrm{dw}$; other compounds such as PFDA or 6:2FTSA remained undetected in this matrix. Details are shown in SI (Table S6).

\subsection{Gammarid survival, PFAS accumulation and elimination}

Organisms from the reference site (La Mouge) displayed a limited contamination by a range of PFCAs (PFOA, PFNA, PFDA, PFDoDA and PFTrDA, all around 0.1-0.0.3 $\mathrm{ng} \mathrm{g}^{-1}$ (ww), and PFOS $\left(0.93 \pm 0.2 \mathrm{ng} \mathrm{g}^{-1} \mathrm{ww}\right)$. After acclimatization for 3 weeks, all concentrations remained similar, except for PFUnDA, which increased to $0.19 \mathrm{ng} \mathrm{g}^{-1}$ (ww) and PFOS, which fell to $0.09 \pm 0.002 \mathrm{ng} \mathrm{g}^{-1} \mathrm{ww}$ (Table S7 in SI). Gammarid survival was $>75 \%$ in control aquaria, and $>80 \%$ in test aquaria except at T6 (54\%, 66\% and 6\% respectively). Organisms from this aquarium with a low survival rate were not considered further.

PFAS concentrations in OW remained steady during the course of the experiment (Figure S2A in SI), except PFOA (decrease at day 21), PFTrDA ( $<\mathrm{LD}$ at day $7,2.62 \mathrm{ng} \mathrm{L}^{-1}$ at day 15 , and $0.14 \mathrm{ng} \mathrm{L}^{-1}$ at day 21) and PFBS (increase at day 21). PFAS concentrations in PW were in the 1-10 $\mathrm{ng} \mathrm{L}^{-1}$ range (PFPA, PFHpA, PFOA, PFNA, PFUnDA, PFHxS, PFOS) or below (PFDA, PFBS), and steady (Figure S2-B), with two exceptions: PFHxA, which decreased from $116 \mathrm{ng} \mathrm{L}^{-1}$ at day 7 to $81 \mathrm{ng} \mathrm{L}^{-1}$ at day 21 (Figure $\mathrm{S} 2-\mathrm{B}$ ), and PFTrDA which remained undetected. PFAS concentrations were also steady in the sediment (Figure S2-C).

Nine of ten compounds (PFCAs: PFNA, PFUnDA, PFDoDA, PFTrDA; PFOS and precursors: PFOS, MeFOSAA, EtFOSAA, FOSA; 6:2FTSA) displayed significantly higher concentrations in test gammarids at 21 days (T3) compared with control organisms (Table 1). The most accumulated compounds were PFUnDA and PFTrDA, and PFOS to a lesser extent. 
Table 1: Mean PFAS concentration in gammarids in control aquaria and at T3 (ng $\mathrm{g}^{-1}$ wet weight (ww)) ( \pm standard deviation, $n=3)$. (*) significant difference between test and control ( $p$-value $<0.05)$.

\begin{tabular}{|l|l|lc|}
\hline Compounds & $\begin{array}{l}\text { Concentration in gammarids } \\
\text { in control aquaria }\left(\mathrm{ng} \mathrm{g}^{-1} \mathrm{ww}\right)\end{array}$ & $\begin{array}{l}\text { Concentration in gammarids } \\
\left(\mathrm{ng} \mathrm{g}^{-1} \mathrm{ww}\right) \text { at 21 days }\end{array}$ & \\
\hline PFOA & $0.43 \pm 0.14$ & $0.36 \pm 0.04$ & $(*)$ \\
\hline PFNA & $<0.09(\mathrm{LQ})$ & $0.20 \pm 0.01$ & $(*)$ \\
\hline PFUnDA & $0.11 \pm 0.02$ & $2.29 \pm 0.60$ & $(*)$ \\
\hline PFDoDA & $0.12 \pm 0.01$ & $0.39 \pm 0.03$ & $(*)$ \\
\hline PFTrDA & $<0.02(\mathrm{LD})$ & $3.18 \pm 0.19$ & $\left(^{*}\right)$ \\
\hline PFOS & $0.17 \pm 0.07$ & $0.84 \pm 0.17$ & $\left(^{*}\right)$ \\
\hline $6: 2$ FTSA & $<0.01(\mathrm{LD})$ & $0.13 \pm 0.06$ & $\left(^{*}\right)$ \\
\hline MeFOSAA & $<0.04(\mathrm{LQ})$ & $0.11 \pm 0.03$ & $\left(^{*}\right)$ \\
\hline EtFOSAA & $<0.02(\mathrm{LD})$ & $0.16 \pm 0.05$ & \\
\hline FOSA & $<0.02(\mathrm{LQ})$ & $0.14 \pm 0.01$ &
\end{tabular}

235 Concentrations of most PFASs were still increasing at T3 (21 days), so the steady state was not reached at 3 weeks of exposure (Figure 1). 

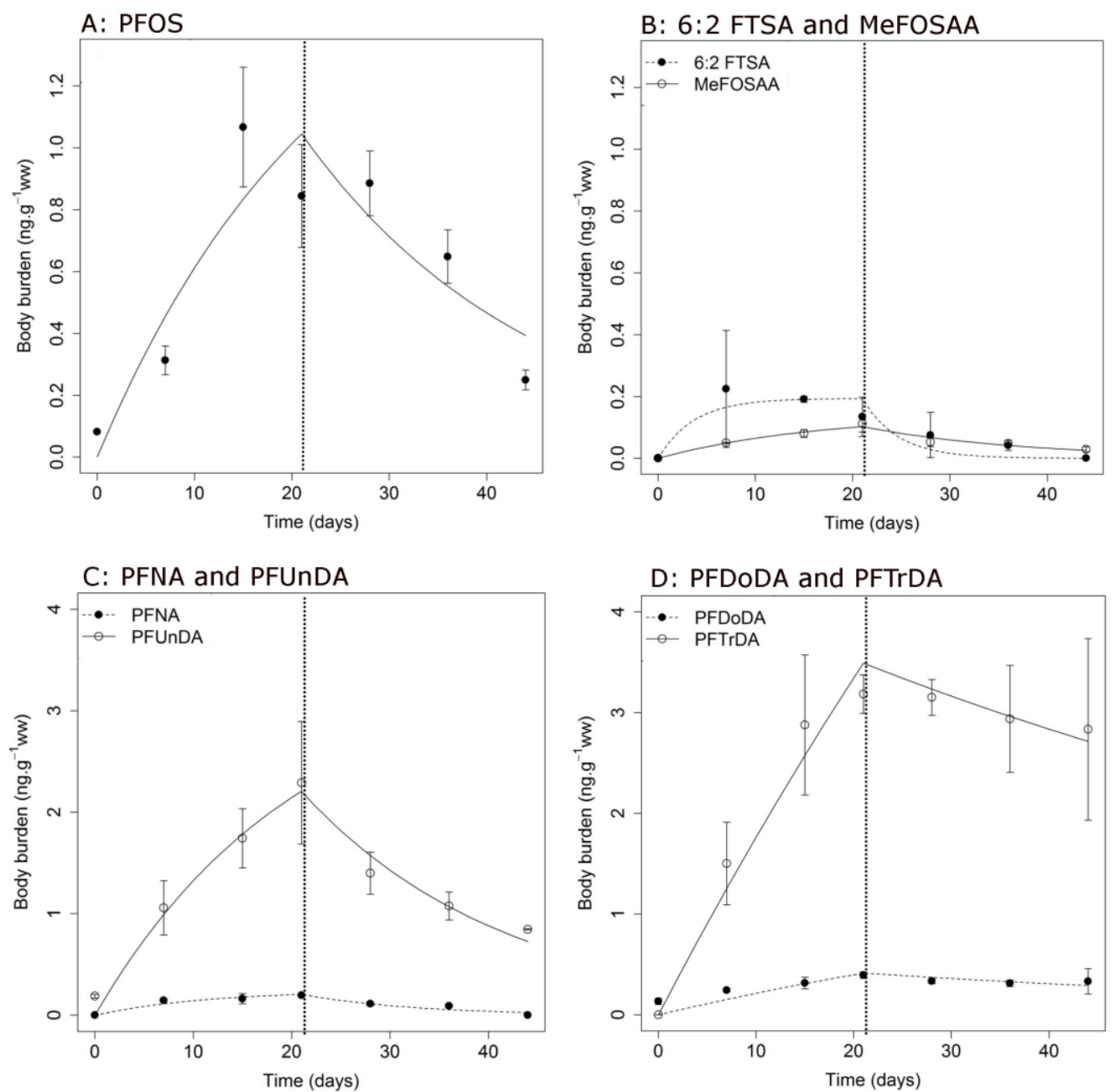

Figure 1 : Accumulation and elimination kinetics of selected PFAS; errors bars represent the standard deviation of measurements $(n=3$, except for the last depuration point T6) - Curves represent model outputs.

MeFOSAA, the fluorotelomer 6:2 FTSA and PFNA were rapidly eliminated after gammarids transfer in uncontaminated water (Figure 1B and C, respectively), with half-lives ranging from 7.5 days for 6:2 FTSA to 10.8 days for MeFOSAA. The elimination was slower for FOSA, PFOS and PFUnDA (Figure 1A and C), with half-lives of 15.0, 19.4 and 14.5 days, respectively). It was not significant at 21 days for PFDoDA and PFTrDA (Figure 1D; Mann-

245 Whitney test, $p$-value > 0.05). 
The results from the accumulation and elimination experiments fitted the two-compartment

model well (Eq. 1; Figures 1 and S3 and S4 in SI): the distance between the observed and

FOSA $\left(\mathrm{R}^{2}=0.54\right)$ and PFDoDA $\left(\mathrm{R}^{2}=0.29\right)($ Table 2$)$. The uptake rates $\left(k_{u}\right)$ ranged from

0.053 to $0.242 \mathrm{~g} . \mathrm{g}_{\mathrm{ww}} \cdot \mathrm{d}^{-1}$ and the elimination rates $\left(k_{e}\right)$ from 0.042 to $0.276 \mathrm{~d}^{-1}$ (Table 2). Given

that elimination was not significant for PFDoDA and PFTrDA, the $k_{e}$ values provided by the

model calculations for these compounds are indicative, as are the corresponding BSAFs.

Table 2: Model outcomes. The values in brackets for PFDoDA and PFTrDA are tentative, because elimination was not significant for these compounds.

\begin{tabular}{|l|c|c|c|c|c|c|c|c|c|}
\hline & \multicolumn{4}{|c|}{ PFCAs } & \multicolumn{5}{c|}{ PFOS, 6:2 FTSA and PFOS precursors } \\
\hline Compounds & PFNA & PFUnDA & PFDoDA & PFTrDA & PFOS & $\begin{array}{c}6: 2 \\
\text { FTSA }\end{array}$ & MeFOSAA & EtFOSAA & FOSA \\
\hline Distance & 0.001 & 0.013 & 0.004 & 0.039 & 0.023 & 0.002 & 0.0001 & 0.001 & 0.001 \\
\hline $\mathrm{R}^{2}$ & 0.899 & 0.965 & 0.290 & 0.968 & 0.804 & 0.782 & 0.947 & 0.821 & 0.537 \\
\hline$k_{u}\left(\mathrm{~g} \mathrm{~g}_{\mathrm{ww}} \cdot \mathrm{d}^{-1}\right)$ & 0.094 & 0.141 & 0.078 & 0.089 & 0.202 & 0.242 & 0.129 & 0.053 & 0.218 \\
\hline$k_{e}\left(\mathrm{~d}^{-1}\right)$ & 0.087 & 0.048 & $(0.015)$ & $(0.011)$ & 0.042 & 0.276 & 0.060 & nd & 0.066 \\
\hline $\mathrm{BSAF}$ & 1.08 & 2.92 & $(5.05)$ & $(8.13)$ & 4.76 & 0.88 & 2.13 & $\mathrm{nd}$ & 3.32 \\
\hline $\begin{array}{l}\mathrm{N} \\
\text { perfluorinated } \\
\mathrm{C}\end{array}$ & 8 & 10 & 11 & 12 & 8 & 6 & 8 & 8 & 8 \\
\hline
\end{tabular}

256

$\mathrm{BSAF}_{\text {kinetic }}$ values tended to increase as the PFCA chain length increased. In addition, BSAF is also higher for PFOS than for PFNA, which has the same number of perfluorinated carbons

262 determined.

\section{Discussion}


The comparison of PFAS concentrations in each compartment (OW, PW, sediment, leaves and gammarids) in control and test aquaria at the beginning and end of the experiment makes it possible to identify the transfers between the compartments and design a conceptual diagram of PFAS transport (Figure 2). A transfer from one compartment to another is assumed when a compound is present in both compartments in test aquaria, but undetected in one of them in controls. PFBA, MeFOSAA and EtFOSAA are present at similar concentrations in both control and test OWs throughout the experiment, while other PFAS concentrations increase by several orders of magnitude, suggesting transfers from PW (e.g. PFHxA, PFHpA, PFHxS) or sediment particles via PW (e.g. PFUnDA). Thus PFUnDA was presumably transferred from sediment to leaves. PFUnDA is both associated to sediment particles and dissolved in PW: therefore gammarids may have taken PFUnDA from both PW and leaves or sediment. PFTrDA concentrations varied widely in OW (range <LD $-2.62 \mathrm{ng}$ $\mathrm{L}^{-1}$ ) but remained undetected in PW. Since the water was not filtered prior to extraction and analysis, the concentrations measured in $\mathrm{OW}$ and $\mathrm{PW}$ represented the total concentrations (dissolved + sorbed to suspended particles). On the other hand, PFTrDA concentrations could be underestimated in PW, as a consequence of sorption to Rhizon ${ }^{\circledR}$ materials. Notwithstanding these uncertainties concerning PFTrDA measurements in water compartments, the higher load on sediment particles as well as its $K_{O C}$ value (Munoz et al., 2015) supports the hypothesis that PFTrDA uptake occurred much more through the ingestion of contaminated particles than from water. This hypothesis is consistent with previous conclusions about the PFCA benthic source signature for Lake Ontario Diporeia (an amphipod species) (Martin et al., 2004).

During the exposure period, gammarid activity mobilized particles, which deposited on the leaves' surface. Two PFAS transfer pathways to the leaves are therefore possible: (i) by diffusion from water, or (ii) from sediment particles and water. These transfers could involve 
the microbial biofilm on the leaves' surface. Indeed, the leaf conditioning before their addition to the aquaria led to the microorganism's colonization (Abelho, 2001; Aßmann et al., 2011) and biofilms are known for accumulating trace elements (Farag et al., 1998; van Hullebusch et al., 2003) as well as organic compounds (Widenfalk et al., 2008; Writer et al., 2011). Nevertheless, PFAS transfer to the leaves themselves was probably limited, because leaves were renewed every week. Like PFUnDA and PFNA, PFOS accumulation by gammarids could have occurred via water (OW) and leaves concurrently. In summary, gammarids accumulate PFASs by two potential contamination routes: the trophic route, i.e. was the main source. The $k_{e}$ values are not affected.

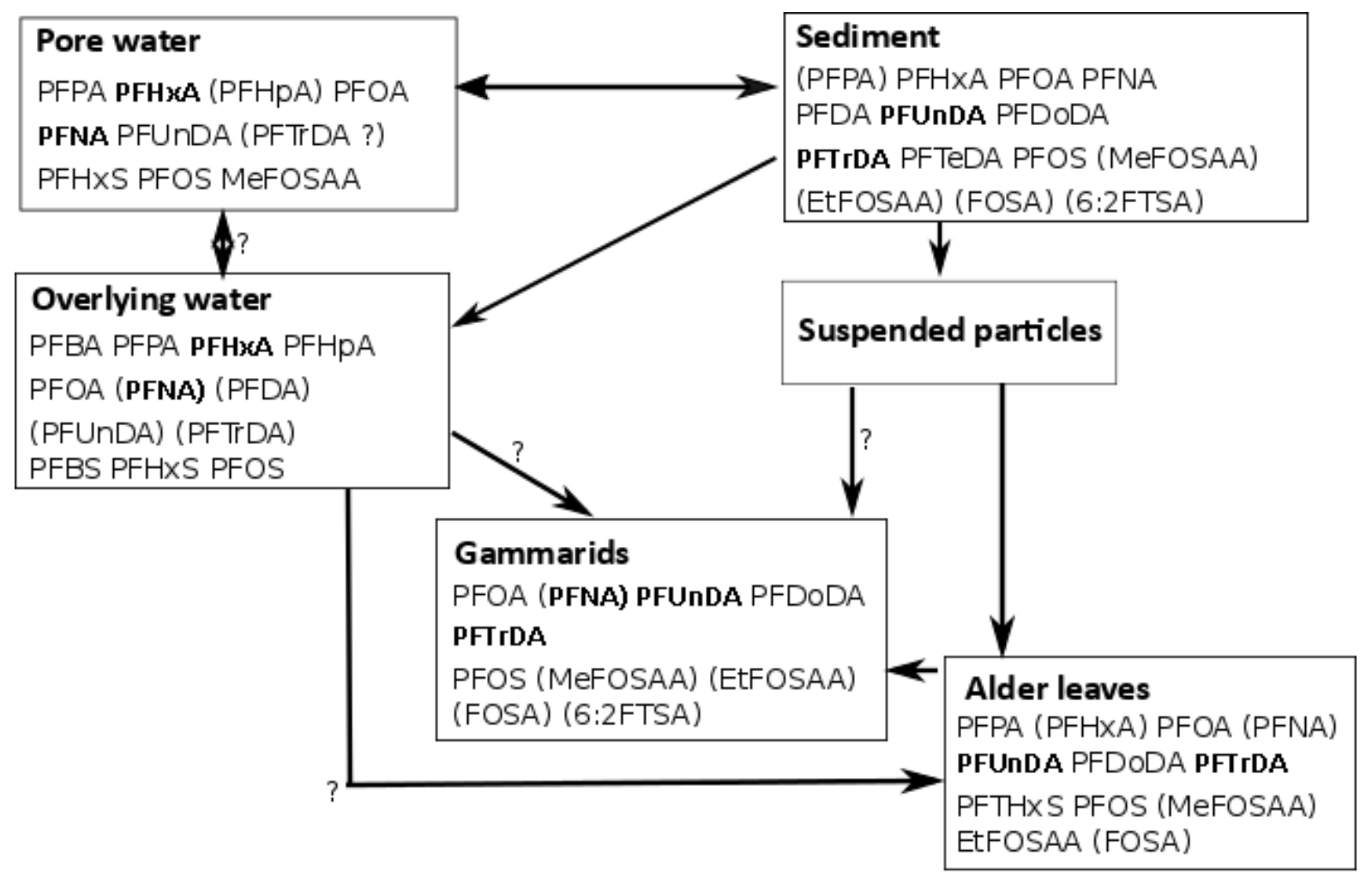


The concentrations observed in gammarids in the present experiment are within the same range as in the few studies that reported PFAS concentrations in crustaceans from the field (Kannan et al., 2005; Haukås et al., 2007). FOSA concentrations $\left(<2 \mathrm{ng} \mathrm{g}^{-1} \mathrm{ww}\right)$ were lower in freshwater amphipods from a Great Lake food web (Kannan et al., 2005) than those found in gammarids in our study. PFOS and PFOA concentrations were higher in marine gammarids (Gammarus wilkitzkii) from the Barents Sea than in the present study, whereas the opposite was found for 6:2 FTSA $\left(0.48 \pm 0.24 \mathrm{ng} \mathrm{g}^{-1} \mathrm{ww}\right)$ (Haukås et al., 2007). Long chain compounds were not often measured in monitoring studies, except in two shrimp species (Peneaus monodon and Metapenaeus ensis) (Loi et al., 2011). (Martin et al., 2004) also analysed a range of PFCAs in the Ontario food-web, observing decreasing concentrations with increasing chain length, but they did not report the respective concentrations in sediments. They stated that the contamination profile observed in Diporeia and sculpin (a benthic-feeding fish species) reflected a benthic source signature. Such comparisons nevertheless remain difficult, because (i) different species were considered and (ii) the exposure concentrations were different and did not necessarily involve water and sediment in all cases.

According to accumulation kinetics, the steady state was not reached at 3 weeks of exposure. For the pesticides chlorpyrifos and pentachlorophenol (Ashauer et al., 2006), the steady state was achieved between 48 and $72 \mathrm{~h}$ for Gammarus pulex: for chlorpyrifos resulted from a decline of the exposure concentration in the test vessel, while for carvedilol and fluoxetine the steady state was not reached in 48 hours (Meredith-Williams et al., 2012). Ashauer et al., (2006) explained the differences between pentachlorophenol and chlorpyrifos by hydrophobicity. Furthermore, Meredith-Williams et al. (2012) assigned the variations in uptake rates of several pharmaceuticals (5-fluorouracil, carbamazepine, diazepam, moclobemide, carvedilol and fluoxetine) at an estimated steady state to the respective 
ionization state. Nevertheless, both studies were conducted in water, with neither sediment nor food present, which presumably lead to different kinetics compared to the present study. These observations and the need for longer equilibration times for PFASs suggest that transport mechanisms across membranes are more complex than simple diffusion. The failure to achieve steady state within 3 weeks could also be due to the formation of PFCAs (or PFSAs) in sediment or gammarids from unanalysed precursors. We nevertheless discarded this hypothesis, bcause (i) PFCA and PFSA concentrations remained steady in sediment during the experiment, and (ii) the corresponding kinetics in sediments are deemed to be very low (Liu and Mejia Avendaño, 2013).

In spite of the failure to achieve the steady state, the determination of the uptake and elimination constant rates allowed determining kinetic BSAFs. For PFCAs, these BSAFs are positively correlated with the number of perfluorinated carbons (Pearson correlation coefficient, 0.958; $p$-value 0.042; when all compounds including PFOS, its precursors and 6:2 FTSA are accounted for, the Pearson coefficient is still 0.797 , and the $p$-value $=0.01$ ). Moreover, the BSAF for PFOS was higher than for PFNA, which has the same number of fluorinated carbons, as already shown in previous studies (Martin et al., 2003a, b; Lasier et al., 2011).

\subsection{Comparison between gammarids and chironomids}

Despite the inherent spatial and temporal variability of the PFAS sediment concentrations in the field, the sediment molecular profile contamination in this study and in studies with the midge Chironomus riparius using a similar design (Bertin et al., 2014; Bertin et al., submitted) are comparable (Table S8). Uptake and elimination rates were estimated with the approach in both studies. The respective kinetics presented several differences between these two species: chironomids did not accumulate PFNA, unlike gammarids. Despite a shorter 
exposure (4 days) according to its life cycle, chironomids' $k_{u}$ for PFUnDA $\left(0.70 \mathrm{~g} \mathrm{~g}_{\mathrm{ww}} \cdot \mathrm{d}^{-1}\right)$, PFTrDA $\left(0.93 \mathrm{~g} \mathrm{~g}_{\mathrm{ww}} \cdot \mathrm{d}^{-1}\right)$, PFOS $\left(1.27 \mathrm{~g} \mathrm{~g}_{\mathrm{ww}} \cdot \mathrm{d}^{-1}\right)$ and FOSA $\left(2.02 \mathrm{~g} \mathrm{~g}_{\mathrm{ww}} \cdot \mathrm{d}^{-1}\right)$ were higher than for gammarids (Table 2). PFAS elimination by chironomids was faster than for gammarids and complete after $42 \mathrm{~h}$. In addition, PFCAs $k_{e}$ values for chironomids were negatively correlated with the carbon chain-length for compounds with more than nine perfluorinated carbons in gammarids. BSAFs were also higher for all PFASs for gammarids than for chironomids, consistent with the gammarids' slower elimination. These differences between these two invertebrates could be explained by different exposure routes related to the organisms' lifestyles and physiology. The chironomid is a benthic invertebrate feeding on organic matter associated with sediment particles, whereas the gammarids are shredder epi-benthic organisms, living in the water column with occasional contact with sediment. For chironomids, the trophic pathways were identified as the main PFAS exposure route (Bertin et al., 2014; Bertin et al., in prep.) while for gammarids the trophic route was predominant for longer chain (>11) PFCAs, and both respiratory and trophic routes were involved for C8-C10 compounds.

\section{Conclusion}

The study results reported here show an accumulation by gammarids of four long-chain PFCAs (PFNA, PFUnDA, PFDoDA and PFTrDA), one PFSA (PFOS), three precursors (MeFOSAA, EtFOSAA, FOSA) and one fluorotelomer (6:2 FTSA) from the sediment. The steady state was not reached at 3 weeks of exposure. In addition, the depuration of PFOS, precursors and 6:2 FTSA was almost complete in 21 days but not for the long-chain PFCAs. The PFCA depuration time increases as the chain length increases. Moreover, in agreement with previous studies (Martin et al., 2003a, b; Lasier et al., 2011), the BSAFs of PFCA values also seem to increase as the chain length increases. The PFAS pathway follows digestive and respiratory routes. In comparison with PFAS bioaccumulation by chironomids, where the 
PFAS accumulation and elimination were fast and complete after $42 \mathrm{~h}$, and the behavioural differences existing between these two organisms, it is clear that lifestyle has an impact on

PFAS exposure routes and subsequent bioaccumulation.

\section{Acknowledgements}

This study was funded by the Rhone-Mediterranean and Corsica Water Agency and the

Rhone-Alps Region within the Rhone ecological restoration plan. The Aquitaine Region and

LABX-45). We thank Linda Northrup (English Solutions, Voiron, France) for copy editing

the text.

\section{References}

Abelho, M., 2001. From Litterfall to Breakdown in Streams: A Review. The Scientific World JOURNAL 1 (http://dx.doi.org/10.1100/tsw.2001.103 ).

Amiard, J.C., Amiard-Triquet, C., Berthet, B., Metayer, C., 1987. Comparative study of the patterns of bioaccumulation of essential $(\mathrm{Cu}, \mathrm{Zn})$ and non-essential $(\mathrm{Cd}, \mathrm{Pb})$ trace metals in various estuarine and coastal organisms. J. Exp. Mar. Biol. Ecol. 106, 73-89 (http://dx.doi.org/10.1016/00220981(87)90148-1).

Armitage, J., Cousins, I.T., Buck, R.C., Prevedouros, K., Russell, M.H., Macleod, M., Korzeniowski, S.H., 2006. Modeling global-scale fate and transport of perfluorooctanoate emitted from direct sources. Environ. Sci. Technol. 40, 6969-6975

Ashauer, R., Boxall, A., Brown, C., 2006. Uptake and elimination of chlorpyrifos and pentachlorophenol into the freshwater amphipod Gammarus pulex. Arch. Environ. Con. Tox. 51, 542548

Ashauer, R., Caravatti, I., Hintermeister, A., Escher, B.I., 2010. Bioaccumulation kinetics of organic xenobiotic pollutants in the freshwater invertebrate Gammarus pulex modeled with prediction intervals. Environ. Toxicol. Chem. 29, 1625-1636 (http://dx.doi.org/10.1002/etc.175) ). Aßmann, C., Rinke, K., Nechwatal, J., Elert, E.V., 2011. Consequences of the colonisation of leaves by fungi and oomycetes for leaf consumption by a gammarid shredder. Freshwater Biol. 56, 839-852 Bertin, D., Ferrari, B.J.D., Labadie, P., Sapin, A., Beaudoin, R., Péry, A., Garric, J., Budzinski, H., Babut, M., in prep. Accumulation and depuration of perfluoroalkyl compounds (PFASs) by midge larvae (Chironomus riparius, Diptera, Chironomidae) exposed to contaminated sediments. Submitted to Chemosphere 
Bertin, D., Ferrari, B.J.D., Labadie, P., Sapin, A., Garric, J., Budzinski, H., Houde, M., Babut, M., 2014. Bioaccumulation of perfluoroalkyl compounds in midge (Chironomus riparius) larvae exposed to sediment. Environ. Pollut. 189, 27-34

Dauchy, X., Boiteux, V., Rosin, C., Munoz, J.F., 2012. Relationship between indusrial discharges and contamination of raw water ressources by perfluorinated compounds. Part I: Case study of a fluoropolymer manufacturing plant. Bull. Environ. Contam. Toxicol. 89, 525-530

Farag, A.M., Woodward, D.F., Goldstein, J.N., Brumbaugh, W., Meyer, J.S., 1998. Concentrations of metals associated with mining waste in sediments, biofilm, benthic macroinvertebrates, and fish from the Coeur d'Alene River Basin, Idaho. . Arch. Environ. Con. Tox. 34, 119-127

Giesy, J.P., Kannan, K., 2001. Global Distribution of Perfluorooctane Sulfonate in Wildlife. Environ. Sci. Technol. 35, 1339-1342 (10.1021/es001834k).

Haukås, M., Berger, U., Hop, H., Gulliksen, B., Gabrielsen, G.W., 2007. Bioaccumulation of per- and polyfluorinated alkyl substances (PFAS) in selected species from the Barents Sea food web. Environ. Pollut. 148, 360-371

Higgins, C.P., McLeod, P.B., Macmanus-Spencer, L.A., Luthy, R.G., 2007. Bioaccumulation of perfluorochemicals in sediments by the aquatic oligochaete Lumbriculus variegatus. Environ. Sci. Technol. 41, 4600-4606

Houde, M., Bujas, T.A.D., Small, J., Wells, R.S., Fair, P.A., Bossart, G.D., Solomon, K.R., Muir, D.C.G., 2006. Biomagnification of perfluoroalkyl compounds in the bottlenose dolphin (Tursiops truncatus) food web. Environ. Sci. Technol. 40, 4138-4144

Houde, M., De Silva, A.O., Muir, D.C.G., Letcher, R.J., 2011. Monitoring of Perfluorinated Compounds in Aquatic Biota: An Updated Review. Environ. Sci. Technol. 45, 7962-7973 (10.1021/es104326w).

Kannan, K., Tao, L., Sinclair, E., Pastva, S.D., Jude, D.J., Giesy, J.P., 2005. Perfluorinated compounds in aquatic organisms at various trophic levels in a Great Lakes food chain. Arch. Environ. Con. Tox. 48, 559-566

Labadie, P., Chevreuil, M., 2011. Partitioning behaviour of perfluorinated alkyl contaminants between water, sediment and fish in the Orge River (nearby Paris, France). Environ. Pollut. 159, 391397 (http://dx.doi.org/10.1016/j.envpol.2010.10.039).

Landrum, P.F., 1989. Bioavailability and toxicokinetics of polycyclic aromatic hydrocarbons sorbed to sediments for the amphipod Pontoporeia hoyi. Environ. Sci. Technol. 23, 588-595

Lasier, P.J., Washington, J.W., Hassan, S.M., Jenkins, T.M., 2011. Perfluorinated chemicals in surface waters and sediments from northwest Georgia, USA, and their bioaccumulation in Lumbriculus variegatus. Environ. Toxicol. Chem. 30, 2194-2201

Lebrun, J.D., Perret, M., Uher, E., Tusseau-Vuillemin, M.H., Gourlay-Francé, C., 2011. Waterborne nickel bioaccumulation in Gammarus pulex: Comparison of mechanistic models and influence of water cationic composition. Aquat. Toxicol. 104, 161-167

Loi, E.I.H., Yeung, L.W.Y., Taniyasu, S., Lam, P.K.S., Kannan, K., Yamashita, N., 2011. Trophic Magnification of Poly- and Perfluorinated Compounds in a Subtropical Food Web. Environ. Sci. Technol. 45, 5506-5513 (http://dx.doi.org/10.1021/es200432n ).

MacNeil, C., Dick, J.T., Elwood, R.W., 1997. The trophic ecology of freshwater Gammarus spp.(Crustacea: Amphipoda): problems and perspectives concerning the functional feeding group concept. Biological Reviews of the Cambridge Philosophical Society 72, 349-364

Martin, J.W., Mabury, S.A., Solomon, K.R., Muir, D.C.G., 2003a. Bioconcentration and tissue distribution of perfluorinated acids in rainbow trout (Oncorhynchus mykiss). Environmental Toxicology and Chemistry 22, 196-204 (http://dx.doi.org/10.1002/etc.5620220126).

Martin, J.W., Mabury, S.A., Solomon, K.R., Muir, D.C.G., 2003b. Dietary accumulation of perfluorinated acids in juvenile rainbow trout (Oncorhynchus mykiss). Environ. Toxicol. Chem. 22, 189-195 (http://dx.doi.org/10.1002/etc.5620220125). 
Martin, J.W., Whittle, D.M., Muir, D.C.G., Mabury, S.A., 2004. Perfluoroalkyl contaminants in a food web from lake Ontario. Environ. Sci. Technol. 38, 5379-5385

Meredith-Williams, M., Carter, L.J., Fussell, R., Raffaelli, D., Ashauer, R., Boxall, A.B.A., 2012. Uptake and depuration of pharmaceuticals in aquatic invertebrates. Environmental Pollution 165, 250-258 (http://dx.doi.org/10.1016/j.envpol.2011.11.029). Statistical Computing, Vienna, Austria. Reiner, J., O'Connell, S., Butt, C., Mabury, S., Small, J., Silva, A., Muir, D.G., Delinsky, A., Strynar, M., Lindstrom, A., Reagen, W., Malinsky, M., Schäfer, S., Kwadijk, C.A.F., Schantz, M., Keller, J., 2012. Determination of perfluorinated alkyl acid concentrations in biological standard reference materials. Anal. Bioanal. Chem. 404, 2683-2692 (http://dx.doi.org/10.1007/s00216-012-5943-5). Spacie, A., Hamelink, J.L., 1985. Bioaccumulation. in: Rand, G.M., Petrocelli, S.R. (Eds.). Fundamentals of Aquatic Toxicology, pp. 495-519.

473 Sun, H., Gerecke, A.C., Giger, W., Alder, A.C., 2011. Long-chain perfluorinated chemicals in digested sewage sludges in Switzerland. Environ. Pollut. 159, 654-662

475 Tlili, K., Labadie, P., Bourges, C., Desportes, A., Chevreuil, M., 2012. Bioaccumulation of polybrominated diphenyl ethers by the freshwater benthic amphipod Gammarus pulex. Arch. Environ. Cont. Tox. 63, 69-76 van Hullebusch, E.D., Zandvoort, M.H., Lens, P.N.L., 2003. Metal immobilisation by biofilms: Mechanisms and analytical tools. Rev Environ Sci Biotechnol 2, 9-33 Widenfalk, A., Lundqvist, A., Goedkoop, W., 2008. Sediment microbes and biofilms increase the bioavailability of chlorpyrifos in Chironomus riparius (Chironomidae, Diptera). Ecotox. Environ. Safe. $71,490-497$ Writer, J.H., Ryan, J.N., Barber, L.B., 2011. Role of biofilms in sorptive removal of steroidal hormones 


\section{$485 \quad$ Figure captions}

486 Figure 2: Accumulation and elimination kinetics of selected PFAS; errors bars represent the standard deviation 487 of measurements ( $n=3$, except for the last depuration point T6) - Curves represent model outputs.

488 Figure 2: Conceptual diagram of PFAS distribution between compartments

\section{Table captions}

490 Table 3: Mean PFAS concentration in gammarids in control aquaria and at T3 (ng. ${ }^{-1}$ wet weight (ww)) ( \pm

491 standard deviation, $n=3) .(*)$ significant difference between test and control ( $p$-value $<0.05)$.

492 Table 4: Model outcomes. The values in brackets for PFDoDA and PFTrDA are tentative, because elimination 493 was not significant for these compounds. 
Potential exposure routes and accumulation kinetics for poly- and perfluorinated alkyl compounds for a freshwater amphipod: Gammarus spp. (Crustacea)

\section{Figure captions}

Figure 1 : Accumulation and elimination kinetics of selected PFAS; errors bars represent the standard deviation of measurements $(n=3$, except for the last depuration point T6) - Curves represent model outputs.

Figure 2: Conceptual diagram of PFAS distribution between compartments 

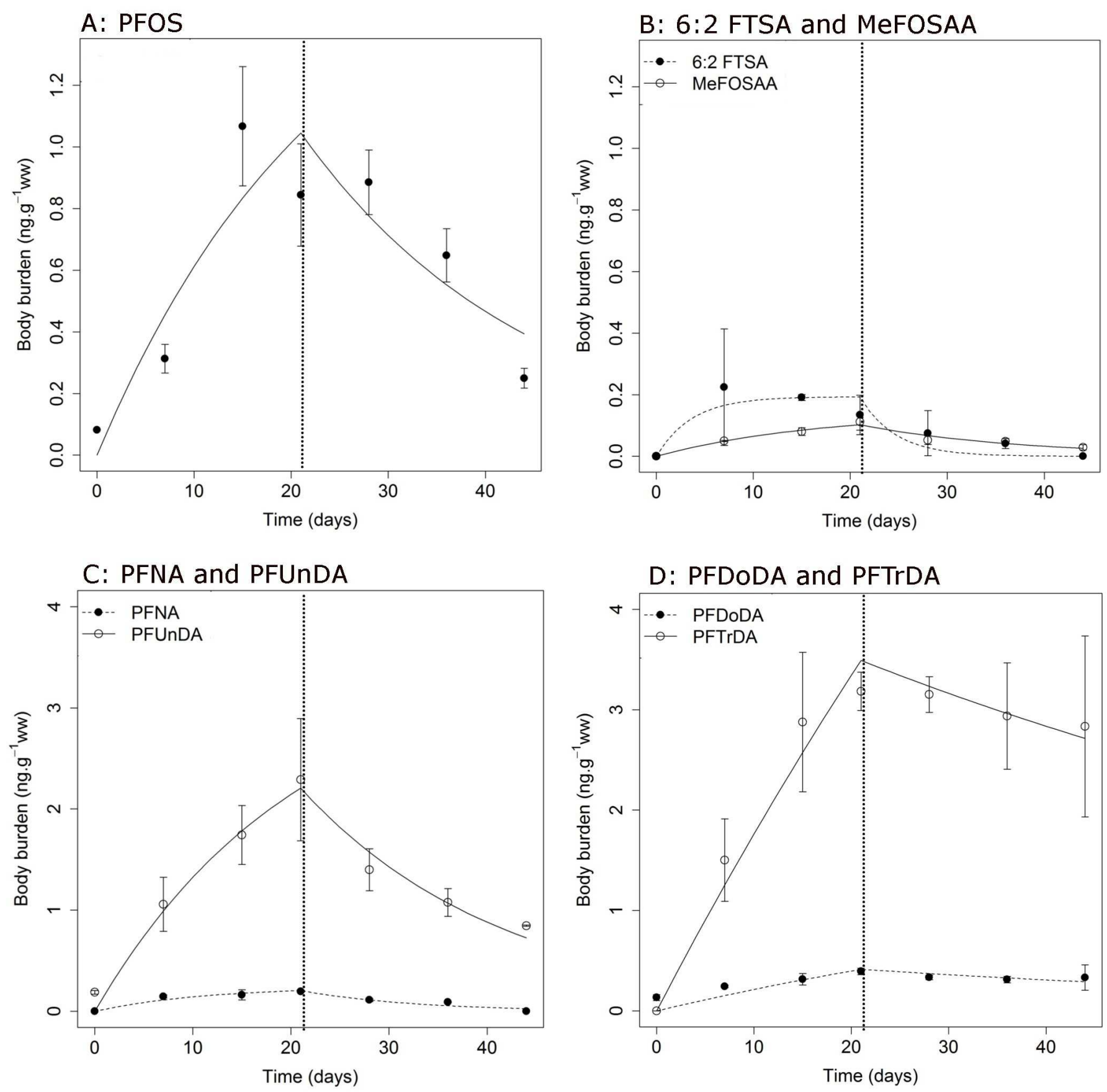
Potential exposure routes and accumulation kinetics for poly- and perfluorinated alkyl compounds for a freshwater amphipod: Gammarus spp. (Crustacea)

Delphine Bertin, Pierre Labadie, Benoît J. D. Ferrari, Alexandre Sapin, Jeanne Garric, Olivier Geffard, Hélène Budzinski, Marc Babut

(Table 1)

\begin{tabular}{|c|c|c|}
\hline Compounds & $\begin{array}{l}\text { Concentration in gammarids } \\
\text { in control aquaria }\left(\text { ng. } \mathrm{g}^{-1} \mathrm{ww}\right)\end{array}$ & 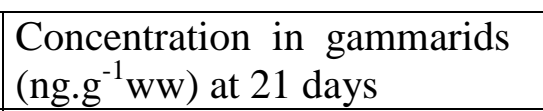 \\
\hline PFOA & $0.43 \pm 0.14$ & $0.36 \pm 0.04$ \\
\hline PFNA & $<0.09$ (LQ) & $0.20 \pm 0.01$ \\
\hline PFUnDA & $0.11 \pm 0.02$ & $2.29 \pm 0.60$ \\
\hline PFDoDA & $0.12 \pm 0.01$ & $0.39 \pm 0.03$ \\
\hline PFTrDA & $<0.02$ (LD) & $3.18 \pm 0.19$ \\
\hline PFOS & $0.17 \pm 0.07$ & $0.84 \pm 0.17$ \\
\hline 6:2 FTSA & $<0.01$ (LD) & $0.13 \pm 0.06$ \\
\hline MeFOSAA & $<0.04$ (LQ) & $0.11 \pm 0.03$ \\
\hline EtFOSAA & $<0.02(\mathrm{LD})$ & $0.16 \pm 0.05$ \\
\hline FOSA & $<0.02(\mathrm{LQ})$ & $0.14 \pm 0.01$ \\
\hline
\end{tabular}




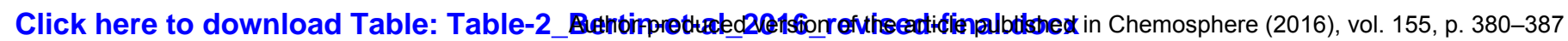

The original publication is available at http://www.sciencedirect.com doi:10.1016/j.chemosphere.2016.04.006

(C). This manuscript version is made available under the CC-BY-NC-ND 4.0 license http://creativecommons.org/licenses/by-nc-nd/4.0/

Potential exposure routes and accumulation kinetics for poly- and perfluorinated alkyl compounds for a freshwater amphipod: Gammarus spp. (Crustacea)

Delphine Bertin, Pierre Labadie, Benoît J. D. Ferrari, Alexandre Sapin, Jeanne Garric, Olivier Geffard, Hélène Budzinski, Marc Babut

(Table 2)

\begin{tabular}{|l|c|c|c|c|c|c|c|c|c|}
\hline & \multicolumn{4}{|c|}{ PFCAs } & \multicolumn{5}{c|}{ PFOS, 6:2 FTSA and PFOS precursors } \\
\hline Compounds & PFNA & PFUnDA & PFDoDA & PFTrDA & PFOS & $\begin{array}{c}6: 2 \\
\text { FTSA }\end{array}$ & MeFOSAA & EtFOSAA & FOSA \\
\hline Distance & 0.001 & 0.013 & 0.004 & 0.039 & 0.023 & 0.002 & 0.0001 & 0.001 & 0.001 \\
\hline $\mathrm{R}^{2}$ & 0.899 & 0.965 & 0.290 & 0.968 & 0.804 & 0.782 & 0.947 & 0.821 & 0.537 \\
\hline$k_{u}\left(\right.$ g. g $\left._{\mathrm{ww} .} \cdot \mathrm{d}^{-1}\right)$ & 0.094 & 0.141 & 0.078 & 0.089 & 0.202 & 0.242 & 0.129 & 0.053 & 0.218 \\
\hline$k_{e}\left(\mathrm{~d}^{-1}\right)$ & 0.087 & 0.048 & $(0.015)$ & $(0.011)$ & 0.042 & 0.276 & 0.060 & nd & 0.066 \\
\hline BSAF & 1.08 & 2.92 & $(5.05)$ & $(8.13)$ & 4.76 & 0.88 & 2.13 & nd & 3.32 \\
\hline $\begin{array}{l}\mathrm{N} \\
\text { perfluorinated } \\
\mathrm{C}\end{array}$ & 8 & 10 & 11 & 12 & 8 & 6 & 8 & 8 & 8 \\
\hline
\end{tabular}

